\title{
Os eus e os outros: a viagem e o senso de alteridade em Mongólia, de Bernardo Carvalho
}

\author{
Adauto Locatelli Taufer
}

\begin{abstract}
Resumo: Este ensaio é o produto de uma comunicação realizada no seminário desenvolvido pelos alunos da disciplina $O$ Romance Brasileiro, ministrada pela Profa. Dra. Gínia Maria Gomes, do Curso de Pós-Graduação em Letras (PPGLET), da UFRGS. Para a concretização deste trabalho, partimos das questões concernentes ao senso de alteridade e à temática da viagem, presentes no romance Mongólia, de Bernardo Carvalho. O recorte que apresentamos parte de uma breve retomada do tema da viagem no universo ficcional na literatura ocidental e culmina com os aspectos relacionados à alteridade e ao jogo de narradores presentes na obra citada. Os diferentes olhares desses narradores, propostos pelo escritor, revelam que, assim como as percepções e impressões são distintas, a verdade, desse modo, o é. Olhares e verdades são, portanto, relativos.
\end{abstract}

\begin{abstract}
This essay is the product of a communication carried through in the seminar developed by the pupils of the subject $O$ Romance Brasileiro, given by Profa. Dra. Gínia Maria Gomes from the Graduation Course in Brazilian Literature (PPGLET), in UFRGS. For the development of this work, we started by the questions concerning alterity and the theme of trip, present in Mongólia, by Bernardo Carvalho. The clipping that we present is a brief look on the subject of trip in the fictional universe in western literature and culminates in the aspects related to alterity and the narrative schemes present in the afore mentioned work. The different looks of these narrators, proposed by the writer, disclose that, their perceptions and impressions are distinct as well as, in this way, the truth. Looks and truths are, therefore, relative.
\end{abstract}

Palavras-chave: alteridade; choque cultural; narrador; viagem

Keywords: alterity; cultural shock; narrative; trip

O estímulo epidérmico, o exótico, o pitoresco prendem só o estrangeiro. Bem outra e mais profunda é a inspiração que leva a representar uma cidade pela perspectiva de um nativo: é a perspectiva de quem se desloca no tempo, em vez de se deslocar no espaço. Walter Benjamin ${ }^{1}$

O tema da viagem tem-se constituído numa fonte inesgotável de possibilidades do universo ficcional e, conseqüentemente, a literatura de viagem tem se firmado como gênero. Essa temática, com efeito, tem sido uma constante no imaginário europeu e, inclusive, no

\footnotetext{
* Doutorando

${ }^{1}$ BENJAMIN, Walter. Obras escolhidas II. São Paulo: Brasiliense, 1987.
} 
imaginário ocidental. A respeito da literatura de viagem, Maria Helena Pereira Toledo Machado (1999) ${ }^{2}$, ao refletir sobre a obra de Mary Louise $\operatorname{Pratt}^{3}$ (1992) afirma que:

Enquanto base de um gênero literário a literatura de viagem serviu para suprir as necessidades de cultura, educação e lazer das nascentes classes médias européias e norte-americanas, construindo, entre outras coisas, um repertório comum a respeito dos povos selvagens e um consenso sobre a necessidade da intervenção do homem branco no mundo pós-colonial que então se esboçava. (MACHADO, 1999, p.12)

O épico relato duma infindável viagem constitui-se numa das mais caras matrizes literárias e culturais européias - a Odisséia ${ }^{4}$. Pululam nas Sagradas Escrituras - Antigo Testamento - histórias de viagens, como a que fez o povo hebreu pelo deserto durante quarenta anos, guiado por Moisés, diretamente orientado por Deus. Viajaram Jonas na barriga de uma baleia; José, filho de Jacó, em direção ao Egito. Esta localidade abrigou José, o carpinteiro, e Maria, a virgem, com seu filho, no episódio da fuga das tropas de Herodes.

Na Idade Média européia - e, posteriormente na Renascença - são recorrentes as narrações de gestas de bravos heróis que vagavam mundo afora. Além disso, muitos viajantes se lançaram em direção às terras místicas, como a Terra da Cocanha, por exemplo, só acessíveis em míticas viagens sonhadas. As viagens de Marco Pólo ${ }^{5}$, de Marco Pólo ${ }^{6}$, Utopia, ${ }^{7}$ de Thomas More ${ }^{8}$ e As viagens de Gulliver, ${ }^{9} \mathrm{de}$ Jonathan Swift ${ }^{10}$, filiam-se a essa

\footnotetext{
${ }^{2}$ Maria Helena Pereira Toledo Machado é a responsável pela revisão técnica da obra Imperial Eyes. Travel Writing and Transculturation, de Mary Louise Pratt, traduzida por Jézio Gutierre.

${ }^{3}$ PRATT, Mary Louise. Os olhos do império: relatos de viagem e transculturação. Bauru: EDUSC, 1999.

${ }^{4}$ HOMERO. Odisséia. São Paulo: Scipione, 1998.

${ }^{5}$ Relatos do navegador genovês que misturam história, relatos de viagem, aventura e fantasia. Com essa obra, há um marco inaugural da literatura de viagens e, pode-se dizer, da literatura fantástica. Nas epopéias de Marco Pólo, são descritos caminhos que parecem levar do Iraque à Índia, do Japão ao Vietnã, passando pelas montanhas e pelos rios da China. Nesses relatos, o viajante faz uma descrição tão minuciosa quanto fantasiosa do Oriente, a mais detalhada descrição da Rota da Seda na época. No entanto, apenas no século XVI, graças à expansão portuguesa, a Ásia passou a ser novamente conhecida pelos europeus. Há controvérsias quanto a categorização dessa obra, uma vez que alguns defendem a idéia de que as narrativas de Marco Pólo são descrições geográficas. Por outro lado, outros questionam o fato de o navegador não ter feito referência às Muralhas da China.
}

${ }^{6}$ POLO, Marco. As viagens de Marco Polo. São Paulo: Scipione, 1995.

${ }^{7}$ Nessa clássica obra, Thomas More - durante uma viagem diplomática a Flandres, em 1515 - em visita ao amigo Erasmo de Roterdã e, profundamente, influenciado pelos escritos de Américo Vespúcio e, sobretudo, pela formação platônica obtida nos tempos acadêmicos, resolveu, num rompante, escrever Utopia, cuja história está centrada num personagem, vindo de uma longa viagem, Rafael Hitlodeu, que lhe relataria o encontro com uma sociedade ideal.

${ }^{8}$ MORE, Thomas. Utopia. Brasília: Ed. da Unb, 2004.

${ }^{9}$ Swift narra um reino em que impera o avanço científico e, além disso, traça, via sátira, um crítico panorama da vida política e social da Inglaterra no século XVII. Embora a intenção alegórica mais direta e pessoal esteja relacionada com a política britânica, sua sátira visa especialmente à humanidade. Os valores humanistas, como a cultura e o saber, são evidentes n'As Viagens de Gulliver.

${ }^{10}$ SWIFT, Jonathan. As viagens de Gulliver. São Paulo: Melhoramentos, 2004. 
vertente viajante européia. Os heróis destas, quase sempre, estão condenados a vagar por estranhas terras - embora apenas imaginadas - como também, de certa forma, o fez Dom Quixote. Portugal, espremido ao norte pelo complexo montanhoso galaico-português e empurrado para o mar pela Espanha, que foi uma sombra ameaçadora - primeiro, terra dos mouros infiéis, depois reino rival mais poderoso e agigantado face ao minúsculo Portugal, esteve geograficamente limitado. Desse modo, não restaram muitas alternativas aos portugueses, pois só lhes restou sair pelo mar. E ao mar eles se lançaram. Afinal, assim como viver, navegar era preciso. Primeiramente, aventuraram-se nas fracassadas cruzadas dos falsos romeiros à Terra Santa; depois, navegaram com o propósito de conquistar o mundo pela força da espada e do canhão.

Vasco da Gama, Fernão de Magalhães, Cabral, a exemplo de Ulisses, lançaram-se ao mar. Luís de Camões, outro viajante impenitente, cantou-os na maior epopéia da Renascença. Legou à nossa cultura - Os lusíadas ${ }^{11}$, de Luiz Vaz de Camões ${ }^{12}$. Fernão Mendes Pinto ${ }^{13}$ vagou pelos novos mundos e deixou à literatura a sua Peregrinação ${ }^{14}$.

Dos cantores medievais que vagavam de aldeia em aldeia, passando por Dom Sebastião e sua frustrada viagem ao norte africano até os angustiados seres de Lobo Antunes, vagantes entre uma África perdida (quiçá nunca conquistada) e uma Lisboa irrecuperável, a literatura portuguesa é uma literatura de viagens. Não só no que se refere à literatura renascentista e medieval, mas também à contemporânea - com os relatos de viagem dos cronistas do descobrimento, a poética de Fernando Pessoa e a ficção de José Saramago, de João de Mello e de Mia Couto, entre outros - a temática da viagem é recorrente e as obras de tais autores reiteram a literatura de viagem como gênero.

$\mathrm{Na}$ literatura brasileira o motivo da viagem também se faz presente. Mário de Andrade, um apaixonado pelo folclore brasileiro, em 1924, iniciou sua viagem do descobrimento do Brasil percorrendo cidades históricas de Minas Gerais. No ano de 1927, esse ícone do movimento modernista brasileiro fez sua primeira viagem em busca de informações sobre os costumes e a cultura regionais. Percorreu o Amazonas e o Peru, o que

\footnotetext{
${ }^{11}$ Poema épico, dividido em dez cantos, no qual a viagem de Vasco da Gama às Índias é o pretexto para Camões relatar a história de Portugal. Inspirado nas antigas epopéias gregas e romanas, sobretudo na Eneida, de Virgílio, a epopéia camoniana, baseada em fatos - comprovados pela história - narra a saga do povo luso.

${ }^{12}$ CAMÕES, Luiz Vaz de. Os lusíadas. São Paulo: Martin Claret, 2004.

${ }^{13}$ PINTO, Fernão Mendes. Peregrinação. Lisboa: Imprensa Nacional. Casa da Moeda, 1988.

${ }^{14}$ Embora tenha sido publicado em 1614, essa obra relata as andanças de Fernão Mendes Pinto no Oriente, em 1569. A escritura memorialista desse autor registra o impacto das civilizações orientais sobre os europeus, constituindo-se numa análise da ação dos portugueses no Oriente. Além do mais, trata-se de uma espécie de testemunho relativo aos comportamentos, atitudes e modos de vida dos orientais e, por isso, o caráter documental de Peregrinação é importante.
} 
resultou no lançamento da obra $O$ turista aprendiz ${ }^{15}$. No ano seguinte, realizou sua segunda incursão pelo interior do Brasil (dessa vez no Nordeste brasileiro), para pesquisar os ritmos que tanto o seduziam. Entre as obras de Mário de Andrade sobre folclore estão: Ensaio sobre música brasileira, Danças domésticas no Brasil e Música de feitiçaria no Brasil. Além desse, outros autores como Guimarães Rosa ${ }^{16}$, em Grande sertão: veredas ${ }^{17}$; Graciliano Ramos ${ }^{18}$, em Vidas secas ${ }^{19}$, Erico Veríssimo ${ }^{20}$, em As aventuras de Tibicuera ${ }^{21}$; Bernardo Carvalho, em Mongólia, entre outros, abordaram o tema da viagem na literatura. Dos relatos de viagens desta última obra se falará nas linhas que se seguem.

Em Mongólia ${ }^{22}$, a escritura de Bernardo Carvalho ${ }^{23}$ suscita as mais diferentes reações nos leitores, pois os temas abordados - viagem, choque cultural e senso de alteridade, entre outros - dependendo do gosto estético e da maturidade literária de cada leitor podem provocar asco, censura, crítica, elogio e êxtase, por exemplo. Desse modo, o objetivo desse texto é propor uma análise como um dos possíveis caminhos, para o reconhecimento de Mongólia como um romance de literatura de viagem. Para tal, a proposta é apresentar os relatos dos personagens-viajantes, com seus respectivos motivos de viagem e as suas impressões em relação ao choque cultural, bipolarizado entre o Oriente e o Ocidente, e ao senso de alteridade.

\section{As vozes dos narradores-viajantes}

Bernardo Carvalho - ao descrever a trajetória de um diplomata brasileiro, na busca de um fotógrafo desaparecido, também brasileiro, nas mutantes e misteriosas paisagens do

\footnotetext{
${ }^{15}$ ANDRADE, Mário de. O turista aprendiz. 2. ed. São Paulo: Duas Cidades, 1983.

${ }^{16}$ ROSA, Guimarães. Grande sertão: veredas. 19.ed. Rio de Janeiro: Nova Fronteira, 2001.

${ }^{17}$ Longo relato das andanças e aventuras do protagonista - Riobaldo, um velho ex-jagunço que há muito deixara de percorrer o sertão, compreendido entre os estados da Bahia e Minas Gerais - a um jovem "doutor" que está de passagem pela sua fazenda.

${ }^{18}$ RAMOS, Graciliano. Vidas secas. 92. ed. Rio de Janeiro: Record, 2003.

${ }^{19}$ Romance da migração nordestina nos períodos de seca, centrado no trágico deslocamento de uma família de retirantes nordestinos - o vaqueiro Fabiano, sua mulher Sinhá Vitória, os dois filhos e a cadela Baleia - que cansados de fugir da seca no sertão, rumam em direção à cidade.

${ }^{20}$ VERISSIMO, Érico. As aventuras de Tibicuera. 30.ed. Rio de Janeiro: Globo, 1987.

${ }^{21} \mathrm{O}$ herói narra sua fantástica viagem através do tempo, iniciada numa taba tupinambá, antes de 1500, e concluída num arranha-céu de Copacabana em 1942. Nessa obra, Erico Verissimo apresenta sua versão da história nacional, publicada em 1937 com o objetivo de fazer frente ao nacionalismo ufanista do Estado Novo.

${ }^{22}$ CARVALHO, Bernardo. Mongólia. São Paulo: Companhia das Letras, 2004.

${ }^{23}$ Em 2002, o colunista da Folha de São Paulo e escritor, por meio de uma bolsa criada em parceria entre a editora portuguesa Livros Cotovia e a Fundação Oriente - de Lisboa -, viajou para a Mongólia. Dessa viagem, resultou Mongólia, romance-documentário ficcional.
} 
território mongol - demonstra o que se pode chamar de um típico etnocentrismo da civilização ocidental.

Em Mongólia, história e literatura se confundem. Esta "bebe" um pouco na fonte daquela, como as referências feitas à dominação chinesa até o princípio do século $\mathrm{XX}$, à varredura política que resultou em intensos massacres da população; à desarticulação da religião budista, com a destruição sistemática dos templos e, conseqüentemente, com a perseguição e o massacre dos monges. Confundem-se história e literatura. Bernardo Carvalho, de fato, percorreu cinco mil quilômetros em terreno mongol. Esse périplo pelo país asiático resultou na construção de um diário de viagem não-linear, truncado, confuso. Nele, três vozes misturadas de viajantes narram a história. Os percalços desses viajantes ficam registrados nos diários de viagem de cada um (N2 e N3), guardados em uma pasta na despensa de um velho diplomata aposentado (N1).

Primeiramente, ao iniciar a leitura da obra, ao leitor é apresentado o narrador (N1), um ex-embaixador brasileiro aposentado que vive no Rio de Janeiro, que conduz o leitor ao longo da trama. Esse narrador-personagem reencontra, na despensa de seu apartamento, uma pasta contendo os diários do fotógrafo desaparecido nas terras da Mongólia. O trecho abaixo, além de ilustrar a procura dos diários de viagem perdidos, revela a condição de viajante do N1:

Fui até a despensa do apartamento, onde, no lugar das provisões, mantenho amontoados os arquivos mortos e as tralhas inúteis que me sobraram de tantas viagens e mudanças, e passei horas à procura da pasta em que devia ter metido aqueles papéis, que encontrara por acaso entre as minhas coisas na embaixada, quando arrumava as malas antes de deixar Pequim, há quatro anos. [O grifo é nosso] (CARVALHO, 2004, p.13) ${ }^{24}$

Esses diários, com efeito, foram encontrados por outro funcionário do Itamaraty, entregues ao diplomata aposentado, que na época do tempo vivido havia sido encarregado da investigação do desaparecimento do fotógrafo-turista brasileiro. Ainda com relação ao N1, é ele que, no início da obra, relata a cena violenta da morte do Ocidental (N2) "num tiroteio entre a polícia e uma quadrilha de seqüestradores, quando ia pagar o resgate do filho menor no morro do Pavãozinho" (CARVALHO, 2004, p.9), demonstrando, desse modo, a ausência de linearidade na tessitura narrativa de Mongólia. O trecho acima, também, revela a condição de viajante desse narrador, que viaja, não a turismo, mas a trabalho: "Fui até a despensa do apartamento, onde, no lugar das provisões, mantenho amontoados os arquivos mortos e as tralhas inúteis que me sobraram de tantas viagens e mudanças". (ibidem)

O diplomata aposentado, também, narra a necessidade de se fazer uma discretíssima investigação diplomática (porque o Brasil não tinha representação diplomática na Mongólia)

\footnotetext{
${ }^{24}$ A partir daqui, todas as vezes que forem feitas citações, fora do corpo do texto, da obra Mongólia, elas conterão apenas o número da página.
} 
sobre o desaparecimento do fotógrafo brasileiro (N3), "filho de um velho empresário, inválido e viúvo, com evidente influência nos bastidores do poder" (id, p.14), no interior da Mongólia, em missão de trabalho:

O embaixador me telefonou do Rio para confirmar que eu havia entendido a prioridade daquela missão. Tínhamos que mandar alguém à procura do rapaz. Por razões que não estavam explícitas e que a nós não cabia discutir, não queriam que as autoridades mongóis fossem avisadas, pelo menos num primeiro momento. (p.14)

Em segundo lugar, há a inserção do segundo narrador (N2), o Ocidental, na trama de Mongólia. Esse outro ser de papel que, inicialmente, se recusa ${ }^{25}$ à missão de investigar o desaparecimento do fotógrafo, é obrigado, no entanto, pelo diplomata aposentado, a ir à Mongólia, tendo a recomendação de ser o mais discreto possível e tentar trilhar os mesmos passos do fotógrafo, refazendo o percurso deste, contratando os mesmos guias. A viagem para o Ocidental, portanto, é imposta, obrigatória. Especificamente a partir da inserção do discurso desse narrador na obra é que se vai perceber o inevitável desconforto entre o oriental e o ocidental: o choque entre as culturas. Embora as questões relativas ao choque cultural sejam tratadas posteriormente, quando se tratar da alteridade, o trecho a seguir revela certo desconforto do Ocidental em terras estrangeiras:

$\mathbf{1}^{\mathbf{0}}$ de junho. Faz uma semana que estou aqui. Uma bruma baixa cobre a cidade, faz um calor opressivo. Tem sido assim desde que cheguei. Como em Xangai. Mas ao contrário do que acontece em Xangai, a escala arquitetônica é inumana. Pequim é uma cidade de extremos. [...] São grandes espaços, esplanadas e avenidas para cidadãos subjugados e obedientes, ao lado dos últimos resquícios dos velhos hutongs, aglomerações caóticas e labirínticas, favelas de alvenarias e pedra baseadas na antiga disposição dos acampamentos mongóis. [Grifo do autor] (p.17)

Finalmente, uma terceira voz compõe o trio de narradores de Mongólia. É a voz do fotógrafo brasileiro (N3), "um profissional que tinha sido contratado por uma revista de turismo no Brasil para atravessar a Mongólia de norte a sul” (id, p.33). Para essa personagem, a viagem se configura como algo prazeroso. Além de ser uma viagem de trabalho, a condição desse viajante é a de um curioso aventureiro. O trecho abaixo ilustra o início da escritura do diário do fotógrafo viajante em terras mongóis:

5 de julho. [...] É o começo da minha viagem. Meu objetivo é fotografar os tsaatan, criadores de renas que vivem isolados na fronteira com a Rússia, entre a taiga e as montanhas. Estão em vias de extinção. Abastecemos em Khatgal. O vilarejo tem jeito siberiano. [...] (p.39)

Como se pôde perceber, o modo de narrar, em Mongólia, é bastante diversificado. $\mathrm{Na}$ visão de Edna Tarabori Calobrezi (2001, p.63) "tanto pela alternância das vozes, a partir dos

\footnotetext{
${ }^{25} \mathrm{O}$ motivo pelo qual o Ocidental recusa a missão de resgatar o fotógrafo brasileiro, em terras mongóis, é revelado ao leitor de uma forma muito sutil, quase elíptica, pelo N1. O N1 entregou um dossiê completo acerca do fotógrafo desaparecido. Nesse documento constava o nome do pai do fotógrafo que, coincidentemente, era o mesmo nome do pai do Ocidental. O fotógrafo e o Ocidental, portanto, eram irmãos.
} 
dois diários de viagens, quanto pela técnica do comentário" ${ }^{26}$, ou seja, as explicações e reflexões que o diplomata aposentado tece após ler os relatos dos viajantes. Esse hibridismo de narradores integra a composição da narrativa e, ao mesmo tempo, proporciona diferentes pontos de vista ao leitor. Tal recurso de cruzar narradores conta com um recurso gráfico, no romance de Bernardo Carvalho, pois os três relatos são grafados com tipos de letras distintas, como se pode constatar, a seguir:

(Fonte: CARVALHO, 2004, p.30)

Fui eu que o fiz ler $O$ puxador de riquixá e Terra felina, de Lao She. Fui eu que o levei a galerias de arte. O que ele dizia tinha a ver ao mesmo tempo com uma resistência ao que não compreendia e com uma impaciência, uma pressa de compreender. Era um sujeito torturado por vontades que à primeira vista

Fig. 1 - Marca tipográfica do N1

(Fonte: id., 2004, p. 31)

Pela manhã, ao tentar trocar cem dólares em cheques de viagem, porque precisava de iuanes para o táxi e a taxa de aeroporto, o funcionário na recepção do hotel, quando viu meu passaporte, quis saber de que país eu vinha. Perguntei se fazia diferença. Um ameri-

Fig. 2 - Marca tipográfica do N2

(Fonte: id., 2004, p. 41)

Estamos em terra de xamãs. Quem viaja por toda a Mongólia vai encontrando pelo caminho amontoados de pedras, como pequenas pirâmides com faixas e estandartes azuis fincados no topo. São os ovoos, que marcam os locais onde há maior proximidade entre o céu e a terra e maior facilidade de comunicação com os espíritos. Designados pelos xamãs, em geral ficam em

Fig. 3 - Marca tipográfica do N3

\section{Os eus e outros: o senso de alteridade}

A experiência da viagem e da literatura de viagem se apresenta como espaço privilegiado para a articulação do senso de alteridade. Possibilitando, por meio do deslocamento, que os sujeitos-viajantes reflitam a respeito de si próprios e, principalmente, a respeito do outro. Para Maria Helena Toledo Machado (2000, p. 281-9), “a literatura de viagem, além disso, abre espaço para a construção, por contraste, de um discurso sobre a

\footnotetext{
${ }^{26}$ Cf. CALOBREZI, Edna Tarabori. Morte e alteridade em Estas Estórias. São Paulo: Editora da Universidade de São Paulo, 2001.
} 
alteridade e sobre o papel do ocidente no domínio, na condução e na absorção das sociedades não-ocidentais". ${ }^{27}$ Enquanto experiência individual do sujeito-viajante, para essa autora ${ }^{28}$,

a viagem para terras longínquas surge claramente como metáfora da viagem interior, suportando experiências pioneiras de subjetividade e auto-conhecimento. Enquanto discurso auto-reflexivo do homem que, ao viajar, observa, reflete e cataloga terras estranhas e povos selvagens, a viagem realizava uma apropriação discursiva das áreas coloniais, dando origem a uma configuração nova, porém extremamente efetiva de conquista [...]. (MACHADO, 2000, p.284)

Em Mongólia, o espaço destinado ao outro assume um dimensão astronômica. O outro, o estranho, é um complemento da identidade do viajante. Partindo dessa perspectiva, o estranho permite compreender a alteridade como parte integrante do mesmo. Para Edna Tarabori Calobrezi (2001) ${ }^{29}$,

Após a descoberta do inconsciente por Freud, a alteridade ganhou maior amplitude diante da noção de que "somos divididos", abrigamos o outro dentro de nós, e a noção do duplo consolida essa posição freudiana, levando Kristeva a assegurar que a estranheza constitui o psiquismo humano e, "a partir do outro, eu me reconcilio com a minha alteridade-estranheza" [Destaques da autora] (CALOBREZI, 2001, p.22)

Ainda segundo essa autora, que tece considerações a partir dos escritos de Freud, "o outro pode ser visto como modelo, objeto, auxiliar ou oponente, dependendo das relações estabelecidas pelo indivíduo com os seus" (id, 2001, p. 25) Em Mongólia, a alteridade é percebida sob o ângulo do choque cultural, em que o diferente é sempre o outro. O convívio dos narradores com os grupos sociais mongóis se processa de modos distintos: para o Ocidental, o contato com os habitantes da Mongólia propicia e favorece ao desencontro, ao desajuste. É, sobretudo, por meio do contato desse personagem com os mongóis que se evidencia o profundo embate entre as culturas ocidental e oriental. A presença desse narrador em Mongólia reitera o que Wladimir Krysinski ${ }^{30}$, em Discurso de viagem e senso de alteridade, denomina de alteridade radical. Nessa perspectiva de alteridade, o outro desperta horror no Ocidental, que está, quase sempre, de mãos atadas por não conseguir se adaptar às diferenças culturais, à barreira da linguagem e da cultura, sobretudo. A experiência da viagem, para ele, é sofrida e frustrante. O trecho abaixo é significativo para ilustrar o choque cultural e a presença ameaçadora do outro:

[...] Estou nas mãos de Purevbaatar. Dependo dele para tudo e não confio no que diz ou traduz. [...] Não tenho escolha. Tenho que me acostumar com o ritmo das coisas - não adianta querer ir direto ao assunto ou confrontar Purevbaatar. Reagiu ofendido na poucas vezes em que

\footnotetext{
${ }^{27}$ MACHADO, Maria Helena Toledo. Os olhos do império. Relatos de viagem e transculturação. Revista Brasileira de História. USP, volume 20, número 39, p. 281-289, 2000.

${ }^{28}$ Op. cit.

${ }^{29}$ Op. cit.

${ }^{30}$ KRYSINSKI, Wladimir. "Discurso de viagem e senso de alteridade". Organon. Instituto de Letras/UFRGS, volume 17, número 34, p. 21-43. Visagens da viagem.
} 
o pus contra a parede. É impossível saber se estou sendo enganado ou não. E, como se não bastasse, tenho que me acostumar com a falta de banho. É apenas o primeiro dia de viagem [...].[O grifo é nosso] (p.119)

Outro trecho significativo que revela a alteridade radical em Mongólia relaciona-se ao momento em que o Ocidental e seu guia, Purevbaatar, são surpreendidos por quatro mongóis. A presença desses sujeitos desperta a sensação de pânico no estrangeiro viajante:

[...] um carro desponta lá longe, [...] Pára a vinte metros das nossas barracas. São quatro sujeitos de Altai. Vêm nos ver. [...] E, por incrível que pareça, resolvem se banhar no lago bem na frente das nossas barracas. A água está gélida. São uns sujeitos estranhos. Purevbaatar diz que conhece um deles. [...] Se se conhecem, por que não se cumprimentam? Como não entendo os códigos locais, começo a ficar apreensivo. Eles pulam, brincam, falam alto e arrotam na água bem diante de nós. Parece provocação. Saem da água tiritando, se enrolam em toalhas, ligam o rádio do carro e começam a cantar e a beber. E eu, a me irritar. Estão bêbados. [...] Tento me convencer de que o intruso é gentil, mas a diferença cultural cria uma tensão permanente. Na incompreensão, só me resta escolher entre o paternalismo e o medo. Começo a entrar em pânico. Continuo escrevendo para disfarçar.[...] [O grifo é nosso] (p.140-141)

A partir do trecho acima, pode-se deduzir que a perspectiva de viagem, para esse narrador, se articula com os objetos visualizados, deformando-os pelo seu olhar expressionista, e se fundamenta na oposição à cultura do outro como complemento da sua identidade $^{31}$, ou seja, quanto mais o Ocidental (eu) se choca com os orientais (outro), (nessa passagem do eu para o outro em que ocorre a absorção/rejeição do outro), mais ele (re)afirma a sua identidade e a sua cultura ocidentais.

Se, por um lado, para o Ocidental o senso de alteridade é radical, para o fotógrafo brasileiro, entretanto, ele é mais ameno, uma vez que esse personagem se coloca numa posição de espectador, no que se refere ao choque entre as diferentes culturas. $\mathrm{O}$ embate entre o eu e o outro, desse modo, é suavizado. Sua atitude, enquanto viajante varia da mera curiosidade ao empenho de tentar se inserir noutra cultura. Seu olhar é mais complacente com aquilo que é diferente:

Os tsaatan são criadores de renas e, ao contrário dos outros nômades da Mongólia e do Cazaquistão, moram em tendas cônicas. [...] Os tsaatan são da etnia turva e falam uma língua próxima do turco. No geral, são simpáticos e receptivos, como os mongóis. [...] (p. 43)

A distinção entre os olhares lançados sobre o outro pode ser verificada na tessitura narrativa que o diplomata aposentado (N1) propõe ao comentar os outros diários de viagem que se entretecem em Mongólia:

De alguma forma o desaparecido e o Ocidental tinham uma afinidade sinistra nas suas idéias etnocêntricas. A diferença, como eu acabaria entendendo, era que o desaparecido ainda tentava tratar o mundo como aliado. Era mais ingênuo ou otimista. O Ocidental não fazia esse esforço. O desconforto o levava a assumir com naturalidade o papel adversário. Debatia-se com o mundo. [O grifo é nosso] (p. 50)

\footnotetext{
${ }^{31}$ SEIXO, Maria Alzira. Poéticas da viagem na literatura. Lisboa: Cosmos, 1998.
} 
Se o Ocidental privilegia o monólogo, o fotógrafo prioriza o diálogo, uma vez que os motivos de viagens desses dois personagens são distintos. Este tem o objetivo de fotografar os tsaatan, criadores de renas que vivem isolados na fronteira com a Rússia, entre a taiga e as montanhas; aquele tem uma missão diplomática (trazer o cidadão desaparecido ao seio de seu país) e pessoal (encontrar o irmão desaparecido e promover o resgate de suas origens) a cumprir.

Relato de viagem, choque entre diferentes culturas e senso de alteridade são temas que permeiam Mongólia, de Bernardo Carvalho. Viagem não é só deslocamento no espaço e no tempo, mas é, também, transformação e ultrapassagem de fronteiras. O regresso é diferente da partida. A experiência da viagem modificou, de um certo modo, o destino do desaparecido e do Ocidental, seja pela identificação a partir do reconhecimento dos laços parentais, seja pela distinção de olhares lançados sobre outra cultura. Os diferentes olhares desses narradores propostos pelo escritor revelam que, assim como as percepções e impressões são distintas, a verdade, desse modo, o é. Olhares e verdades são, portanto, relativos.

\section{Referências}

ANDRADE, Mário de. O turista aprendiz. 2. ed. São Paulo: Duas Cidades, 1983.

BENJAMIN, Walter. Obras escolhidas II. São Paulo: Brasiliense, 1987.

CALOBREZI, Edna Tarabori. Morte e alteridade em Estas Estórias. São Paulo: Editora da Universidade de São Paulo, 2001.

CAMÕES, Luiz Vaz de. Os lusíadas. São Paulo: Martin Claret, 2004.

CARVALHO, Bernardo. Mongólia. São Paulo: Companhia das Letras, 2004.

HOMERO. Odisséia. São Paulo: Scipione, 1998.

KRYSINSKI, Wladimir. "Discurso de viagem e senso de alteridade". Organon. Instituto de Letras/UFRGS, volume 17, número 34, p. 21-43. Visagens da viagem.

MACHADO, Maria Helena Toledo. Os olhos do império. Relatos de viagem e transculturação. Revista Brasileira de História. USP, volume 20, número 39, p. 281-289, 2000 .

MORE, Thomas. Utopia. Brasília: Ed. da Unb, 2004.

PINTO, Fernão Mendes. Peregrinação. Lisboa: Imprensa Nacional. Casa da Moeda, 1988. 
POLO, Marco. As viagens de Marco Polo. São Paulo: Scipione, 1995.

PRATT, Mary Louise. Os olhos do império: relatos de viagem e transculturação. Bauru: EDUSC, 1999.

RAMOS, Graciliano. Vidas secas. 92. ed. Rio de Janeiro: Record, 2003.

ROSA, Guimarães. Grande sertão: veredas. 19.ed. Rio de Janeiro: Nova Fronteira, 2001.

SEIXO, Maria Alzira. Poéticas da viagem na literatura. Lisboa: Cosmos, 1998.

SWIFT, Jonathan. As viagens de Gulliver. São Paulo: Melhoramentos, 2004.

VERISSIMO, Erico. As aventuras de Tibicuera. 30.ed. Rio de Janeiro: Globo, 1987. 